\title{
Perspectives for Sustainable Aviation Biofuels in Brazil
}

\author{
Luís A. B. Cortez, ${ }^{1,2}$ Francisco E. B. Nigro, ${ }^{3}$ Luiz A. H. Nogueira, ${ }^{2}$ \\ André M. Nassar, ${ }^{4}$ Heitor Cantarella, ${ }^{5}$ Márcia A. F. D. Moraes, ${ }^{6}$ Rodrigo L. V. Leal, ${ }^{2}$ \\ Telma T. Franco, ${ }^{2,7}$ Ulf F. Schuchardt, ${ }^{8}$ and Ricardo Baldassin Junior ${ }^{1,2}$
}

\author{
${ }^{1}$ School of Agricultural Engineering (FEAGRI), State University of Campinas (UNICAMP), Avenue Candido Rondon No. 501, \\ 13083-875 Campinas, SP, Brazil \\ ${ }^{2}$ Interdisciplinary Center for Energy Planning (NIPE), State University of Campinas (UNICAMP), P.O. Box 6192, \\ 13083-970 Campinas, SP, Brazil \\ ${ }^{3}$ Polytechnic School (EPUSP), University of Sao Paulo (USP), P.O. Box 61548, 05424-970 São Paulo, SP, Brazil \\ ${ }^{4}$ Agroicone, Avenida General Furtado do Nascimento No. 740, Cj. 81, 05465-070 São Paulo, SP, Brazil \\ ${ }^{5}$ Soils and Environmental Resources Center, Agronomic Institute of Campinas (IAC), P.O. Box 28, 13020-902 Campinas, SP, Brazil \\ 6"Luiz de Queiroz" College of Agriculture (ESALQ), University of São Paulo (USP), Avenue Padua Dias No. 11, P.O. Box 9, \\ 13400-970 Piracicaba, SP, Brazil \\ ${ }^{7}$ School of Chemical Engineering (FEQ), State University of Campinas (UNICAMP), P.O. Box 6011, 13083-852 Campinas, SP, Brazil \\ ${ }^{8}$ Institute of Chemistry (IQ), State University of Campinas (UNICAMP), P.O. Box 6154, 13083-970 Campinas, SP, Brazil
}

Correspondence should be addressed to Luiz A. H. Nogueira; horta@unifei.edu.br

Received 24 June 2015; Accepted 16 November 2015

Academic Editor: Youngbin Yoon

Copyright (C) 2015 Luís A. B. Cortez et al. This is an open access article distributed under the Creative Commons Attribution License, which permits unrestricted use, distribution, and reproduction in any medium, provided the original work is properly cited.

\begin{abstract}
The aviation industry has set ambitious goals to reduce carbon emissions in coming decades. The strategy involves the use of sustainable biofuels, aiming to achieve benefits from environmental, social, and economic perspectives. In this context, Brazilian conditions are favorable, with a mature agroindustry that regularly produces automotive biofuel largely adopted by Brazilian road vehicles, while air transportation has been growing at an accelerating pace and a modern aircraft industry is in place. This paper presents the main conclusions and recommendations from a broad assessment of the technological, economic, and sustainability challenges and opportunities associated with the development of drop-in aviation biofuels in Brazil. It was written by a research team that prepared the initial reports and conducted eight workshops with the active participation of more than 30 stakeholders encompassing the private sector, government institutions, NGOs, and academia. The main outcome was a set of guidelines for establishing a new biofuels industry, including recommendations for (a) filling the identified research and development knowledge gaps in the production of sustainable feedstock; (b) overcoming the barriers in conversion technology, including scaling-up issues; (c) promoting greater involvement and interaction between private and government stakeholders; and (d) creating a national strategy to promote the development of aviation biofuels.
\end{abstract}

\section{Introduction}

Aviation is essential in modern society, transporting people and goods rapidly and safely around the world, with energy consumption essentially based on oil products. In 2011, 312 million $\mathrm{m}^{3}$ of jet fuel was consumed globally, corresponding to $6.4 \%$ of oil refinery output [1]. In Brazil, the jet fuel consumption in that year was about 7 million $\mathrm{m}^{3}, 75 \%$ supplied by domestic refineries [2]. The Brazilian consumption of jet fuel is growing quickly, with an annual growth rate of approximately $5 \%$ and projected to reach 11 to 12 million $\mathrm{m}^{3}$ by the year 2020 [3].

Fuel represents the most important operational cost for an airline. As a world average, fuel currently represents $33 \%$ of the airlines' operational costs (compared with 10-15\% in the past decade) [4], and in Brazil this burden is even higher, representing approximately $40 \%$ of the operational cost for the airlines [5]. Besides this high share of total costs, 
the volatility of the oil prices is another concern, introducing significant hurdles for planning and management in these companies.

Historically, significant gains in fuel efficiency have been achieved by operational and technical improvements (such as higher load factors, more efficient engines, and lighter airframes). However, these efficiency gains have not been able to compensate for the fast growth of the aviation industry, increasing the concern about the environmental impact of fossil fuel utilization [6]. Although air transport currently accounts for approximately $2 \%$ of anthropogenic $\mathrm{CO}_{2}$ emissions, these emissions by worldwide aviation are forecast to reach nearly six times the current figure by 2050 . In the Brazilian context, where road transportation has been using renewable fuels (ethanol and biodiesel) for decades, the share of transportation sector $\mathrm{CO}_{2}$ emissions caused by aviation could reach $12 \%$ by 2020 [7]. Sustainable biofuels can potentially mitigate these emissions [8-12].

To address the threat of climate change and reduce emissions from the aviation sector, some public policy suggestions have been put forward. In this regard, the most relevant measure is the European Union Emissions Trading Scheme (EU ETS), launched in 2005 to be introduced in progressive stages representing relevant additional costs to the sector [13]. In April 2013, the EU decided to temporarily suspend ETS implementation, to allow time for the International Civil Aviation Organization (ICAO) to reach a global agreement to reduce carbon emissions. In October 2013, the ICAO Assembly agreed to develop a global market-based mechanism addressing international aviation emissions by 2016, to be applied by 2020 . Until then, countries or groups of countries can implement interim measures [14].

In the aviation industry, there are several initiatives in place to reduce $\mathrm{CO}_{2}$ emissions. In October 2013, the International Air Transport Association (IATA), in agreement with the ICAO initiative, approved the resolution "Implementation of the Aviation Carbon-Neutral Growth Strategy (CNG2020).". The resolution setting out three ambitious targets for addressing carbon emissions is as follows:

(1) $1.5 \%$ average annual fuel efficiency improvement between 2010 and 2020;

(2) carbon neutral growth from 2020;

(3) a reduction of $50 \%$ in net emissions by 2050 compared to 2005 levels [15].

Considering the specific requirements of operational safety, the aviation industry has been developing "dropin biofuels." These are biofuels that have equivalent performance characteristics to fossil fuel in all respects, use the same logistics system (tanks and pipelines), and can be burned in unmodified jet turbines designed to operate with regular jet fuel. To assure that these requirements have been accomplished, the industry and aviation regulatory bodies have adopted the ASTM standards and procedures for certification. Thus after approval of the blend according to ASTM D7566 standard [16], attested by the batch certificate of quality, the biofuel is identified as satisfying ASTM D1655 [17]. It becomes interchangeable with any approved jet fuel and subject to the same requirements as conventional jet fuel. Currently, three processing routes have received ASTM technical certification to be used in blends up to $50 \%$ with conventional jet fuel. Other processes are in the approval stage.

Work to drive costs of producing biofuels down to competitive levels is under way in many parts of the world. Important challenges include availability of suitable feedstocks, uncertainty surrounding the definition of sustainability criteria, scaling-up methods that introduce new technology into integrated feedstock and refining pathways, improvements in logistics and deployment of resources, and a lack of political and policy support for aviation biofuel [18-21].

As a clear signal of the interest and commitment by the aviation industry towards the development of aviation biofuels, there are an increasing number of initiatives promoting them [11, 22, 23]. Hundreds of demonstration flights using different biofuels have been made by more than 20 airlines worldwide, flying with blends of regular jet fuel and aviation grade biofuel made out of a variety of feedstocks including used cooking oil and oil crops such as rapeseed, Jatropha, Camelina, and palm oil. Some companies such as Aeromexico, Alaska Airlines, Lufthansa, and KLM, have made many regular commercial flights using biofuels [24] and several research and development programs joining governmental agencies, airlines, universities, biofuel industries and other stakeholders were launched. They included the Commercial Aviation Alternative Fuels Initiative (CAAFI) in the United States, the European Advanced Biofuels Flight Path Initiative, the Sustainable Way for Alternative Fuels and Energy for Aviation (SWAFEA), the Initiative Towards Sustainable Kerosene for Aviation (ITAKA) in Europe, the Sustainable Aviation Fuels Road Map in Australia and New Zealand, the Plan de Vuelo in Mexico, and the Sustainable Aviation Fuels User Group (SAFUG), with global coverage [25].

In agreement with those initiatives, the Brazilian Alliance for Aviation Biofuels was created in 2010, bringing various Brazilian companies together "to discuss the various aspects of developing sustainable aviation biofuels driven by the growing demand to meet the need to reduce greenhouse gas emissions in aviation as well as providing support for Brazil's energy security" [26]. In the same year, TAM Airlines tested a jet fuel blend composed of $50 \%$ of fuel made from Jatropha seeds produced in Brazil [27]. During the Conference Rio+20, two Brazilian airlines made other demonstration flights employing biofuels: Azul Airlines flew an Embraer E195 using a "drop-in" renewable jet fuel produced in Brazil from sugarcane by Amyris [28] and GOL Airlines flew a Boeing 737-800 using jet fuel blended with biofuel derived from inedible corn oil and used cooking oil supplied by UOP [29].

Considering the previous national experience with the production and use of liquid biofuels (gasoline in all Brazilian gas stations is sold blended with $20-25 \%$ ethanol, diesel fuel contains $5 \%$ biodiesel, and hydrous ethanol is sold to be used in dedicated or flex fuel engines), the existence of a modern local aircraft industry, and the increasing relevance of air transportation (which carried 83 million passengers 


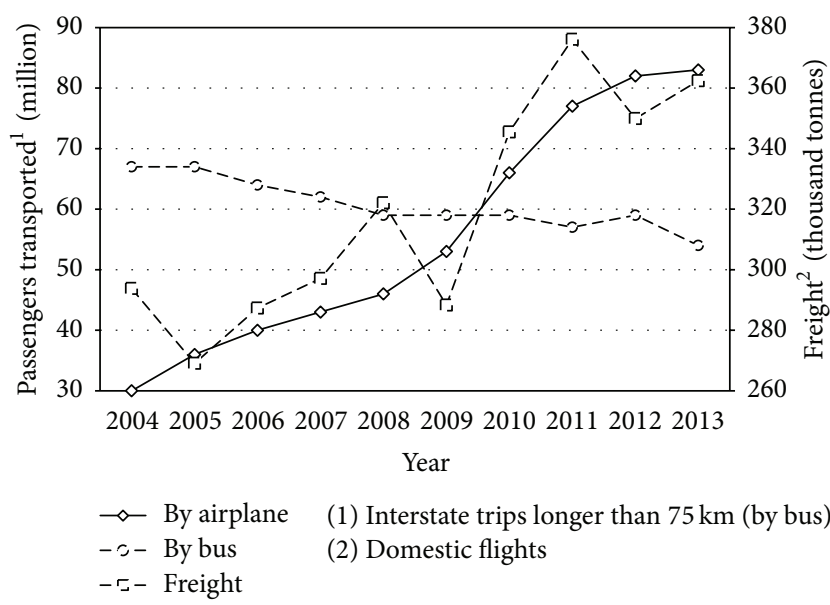

FIGURE 1: Evolution of passenger and freight transportation in Brazil (2004-2013) [31].

in 2013, against 54 million carried by buses on interstate trips longer than $75 \mathrm{~km}$, and 362 thousand tonnes of goods, $23 \%$ more than in 2004, was moved as shown in Figure 1) there is in Brazil a positive case for considering biofuels for aviation. A comprehensive project, Sustainable Aviation Biofuels for Brazil, with the goal of developing a "Flightpath to Aviation Biofuels in Brazil" was developed by FAPESP, the São Paulo Research Foundation, cosponsored by Boeing and Embraer [30]. Based on the results from this project, this paper reviews the conditions to create a sustainable aviation biofuel supply chain in Brazil and suggests an action plan to make low carbon fuels for jet planes a reality in this country. Fuel efficiency can contribute to reducing fuel use and improving energy security, but to achieve the industry's emissions reduction goals will require sustainably produced biofuels that comply with the technical needs of aviation.

\section{Methods}

2.1. The Aviation Industry Perspective and the Project Objectives. A transition towards the use of sustainable biofuels as a substitute for petroleum-based jet fuels in the aviation industry is expected to happen during the coming decades [32]. Although some companies are already producing and selling biofuels for aviation to be used in combination with fossil jet fuels, aviation biofuels have not become a standard part of the airlines' fuel supply, and a fully commercial industry has not yet developed. Considering the aviation industry's vision, the use of biofuels in aviation will have to be effective, efficient, and advantageous from the environmental, social, and economic points of view, to consolidate the expansion of the aviation industry worldwide. Under these conditions, the main objectives of the Sustainable Aviation Biofuels initiative for Brazil were

(a) to develop a roadmap to identify the gaps and barriers related to the production, distribution, and use of biofuels for aviation,

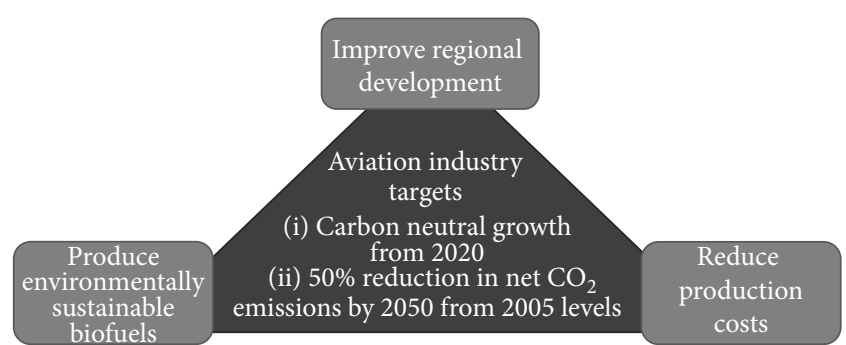

FIGURE 2: Strategic objectives for 2050 for the aviation industry regarding jet fuel substitution by biofuels.

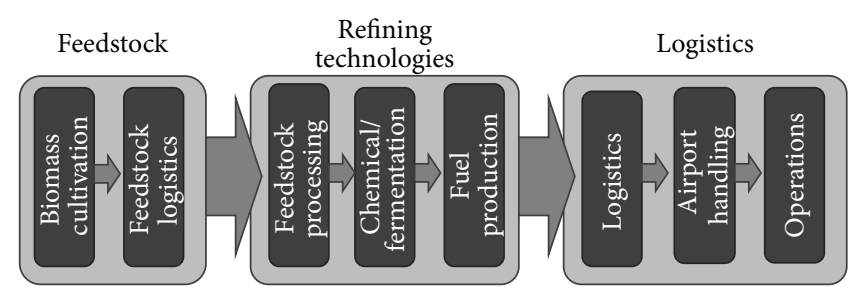

FIgURE 3: Roadmap components for biofuels in the aviation industry.

(b) to create the basis for a research and commercialization agenda to overcome the identified barriers and develop a sustainable aviation biofuel supply chain, with high GHG mitigation potential,

(c) to review and evaluate the regulatory and legal framework to launch a new and innovative industry in Brazil to produce sustainable biofuels for aviation. Figure 2 presents the targets discussed and agreed in the roadmapping process.

2.2. Research Methodology. A roadmapping methodology using workshops to stimulate the discussion was implemented to reach consensus on the gaps and barriers to consider in order to promote sustainable biofuels for aviation. The technology of biofuel production and use was divided into basic components along the value chain, each with a specific focus on corresponding large technological areas relevant to the aviation industry's future vision. Figure 3 shows the main components of the roadmap: feedstock, refining technologies, and logistics, subdivided into the respective topics studied. Sustainability is a critical issue, considered throughout the supply chain.

Eight workshops were organized between May and December 2012, on the following topics: feedstock, refining technologies, sustainability, policy and incentives, logistics and support, R\&D, and commercialization gaps. These workshops gathered stakeholder's perspectives and insights on prospective pathways, providing valuable information needed to develop scenarios/pathways, which were analyzed based on assessing the likelihood of commercial feasibility in the 2015-2022 timeframe, while also considering the longer term timeframe (2050). The workshop results are briefly outlined in the next section. 


\section{Results and Discussion}

\subsection{Main Components of the Aviation Biofuels Roadmap}

3.1.1. Feedstock. Brazil has a strong agricultural tradition and is among the world's leading producers and exporters of many agricultural products, such as soybean, sugarcane, coffee, cotton, maize, tropical fruits, and meats. This relevant position was attained due to abundant land, good climatic conditions, long-term investment in research and development, and an entrepreneurial private sector. Brazil has an interesting combination of a significant area of land already cleared for agriculture, a dynamic agricultural sector displaying strong productivity growth, a large amount of legally protected native vegetation, and human health and safety regulations for rural activities equivalent to urban activities. This remarkable combination places Brazil in a good position from a feedstock supply perspective, if proper policies are implemented, to develop an aviation biofuels program compliant with responsibility principles and sustainability requirements.

The agricultural sector currently occupies $30.4 \%$ of the Brazilian territory (23.3\% pastureland and $7.1 \%$ in agriculture and planted forests), while $65 \%$ of the territory is covered with native vegetation, as summarized in Figure 4. Legally protected native vegetation (conservation units and indigenous reserves) represents $40 \%$ of the total remaining vegetation. Although this is a significant amount of protected land, it is highly concentrated in the Amazon Biome. The other $60 \%$ is located on private properties, from which $50 \%$ of the total remaining vegetation is protected by the National Forest Code, under the legislation approved in 2012. However, annual and perennial crops still occupy a small share of the total agricultural land. The majority of the agricultural land is occupied by pastures, used mainly for beef cattle production.

Pasture-fed cattle based on extensive grazing systems still characterize the pattern of beef production in Brazil. There are still large areas of degraded and low-intensity pastureland that can be utilized more effectively to grow and harvest crops for advanced biofuels production, improving both the environmental and financial value of these lands. The intensification of cattle production will be important in the future to allow the growth of agriculture to continue and avoiding of the pressure for the conversion of natural vegetation. Annual and perennial crops are expanding mainly over pastures areas, although clearing of natural vegetation still occurs. It is estimated that approximately $3 / 4$ of cropland expansion (for annual and perennial crops) in the past 10 years has been directly in pastures and the other $1 / 4$ through the conversion of native vegetation. Most of the expansion in natural vegetation areas is related to cattle expansion. Expansion in annual and perennial crop production, on the other hand, has been primarily caused by yield increase and only secondarily by an increase in area [35].

Availability of feedstock for aviation biofuels, in terms of both production quantities and diverse sources, is not a major concern in Brazil. Most of the crops grown in Brazil are rainfed and do not require irrigation. Its extensive territory has areas with temperate, subtropical, and tropical climates which allow the cultivation of a range of different crops suitable for jet biofuel. Brazil also has a long experience in agriculturalbased biofuels with the sugarcane ethanol program. Around $50 \%$ of the sugarcane produced is used for ethanol. More recently, Brazil implemented the biodiesel blend program, which now uses approximately $26 \%$ of soy oil production.

The most promising potential feedstocks for the initial development of jet biofuel in Brazil are plants that contain sugars and starches but, for the longer term feedstocks, material such as plant oils, lignocellulose, municipal solid wastes, and industrial waste residues can be considered. Brazil is the world's largest producer of sugarcane, second in soybeans, and has the lowest cost of production for eucalyptus wood; therefore, it can produce these classes of feedstocks competitively today. At this stage, these three crops can be considered the natural candidate feedstock to begin the jet biofuels industry in Brazil, depending on the conversion process selected. Proper regulation may be required to meet international standards to ensure that the feedstock for jet biofuel does not compromise food production although, in Brazil historically, food and biofuel production have increased steadily in parallel. In addition, sugarcane and Eucalyptus can be produced with very significant life cycle reductions in $\mathrm{CO}_{2}$ emissions. Oil crops may raise greater concern. It is important to recognize that, even with the more established crops, there is room for improvements to further reduce costs and improve environmental performance. Pine trees are a widely grown forest plant that can be used in addition to Eucalyptus as a feedstock.

Several other crops that currently are not as well positioned may become feasible options as biofuel feedstock. However, they will require some additional effort in $\mathrm{R} \& \mathrm{D}$ to become commercial crops with high yields (Jatropha, Camelina, and sweet sorghum), reduced costs (Jatropha, Camelina, sunflower, peanuts, castor beans, palm, and other oil-bearing crops), or to solve harvesting problems (Jatropha, grasses). Improvements in logistics will be needed for most crops because the transport infrastructure in Brazil is relatively poor and most feedstocks are bulky materials or have a low unit value. This applies to both annual crops and forest products. However, the logistics may be more challenging for palm, which grows well in wet tropical areas that are far away from end-use locations. Brazil's past experience with biofuels also shows that crops which can supply feedstock for diverse applications, for instance, food, fuel, and pulp, have a better chance of success.

Abundant supply of crop residues such as straw, sugarcane bagasse, and forest waste (both from the field and from industry) also makes this class of feedstock an attractive alternative. For these products, collection, and transportation costs, as well as questions of removal rates to preserve soils fertility and structure, are the main gaps and barriers that must be overcome. Therefore, long-term sustainability research projects need to be established to study the impact of forest and agricultural practices on soil and water resources and biodiversity, creating a benchmark for environmental metrics and productivity models.

Municipal solid wastes, tallow, and used cooking oil are other options for biofuel production. Those options recycle 


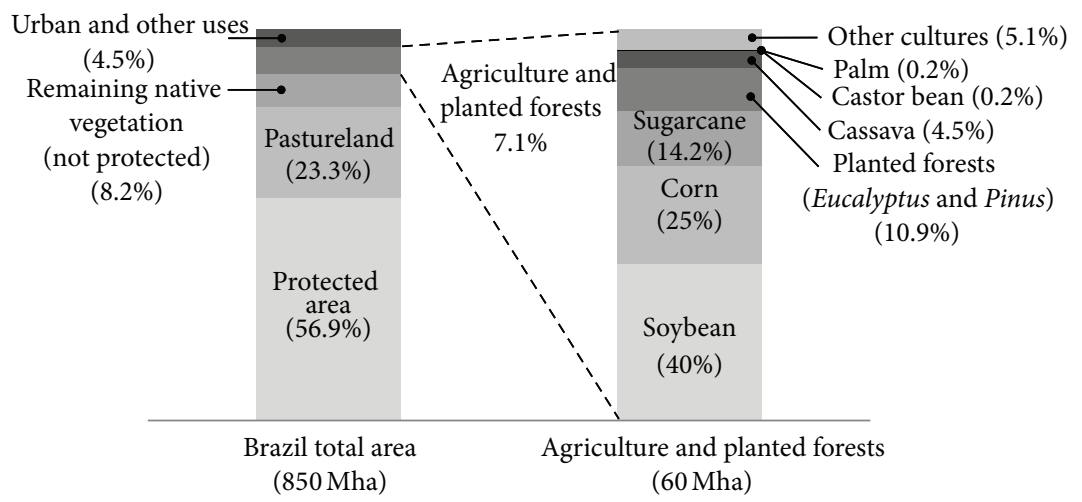

FIGURE 4: Land use and planted area with some potential biofuel feedstocks in Brazil [33, 34].

products that would otherwise require costly disposal and also avoid food security concerns. Tallow is already widely used to produce biofuel in Brazil (it is $15 \%$ of the raw material used to make biodiesel), but the other residues require considerable effort to solve collection and/or separation problems. Other suitable nonfood materials include industrial wastes and flue gases. Among them is the blast furnace exhaust gas rich in $\mathrm{CO}$, widely produced by the Brazilian steel industry, which is one of the world's largest ones. These single point sources of residue feedstocks are inherently of low-value but do not compete with food or affect land use. Gas fermentation technologies can utilize these industrial residues to capture carbon, reducing overall GHG emissions and producing ethanol as an input for jet fuel production.

The general consensus in this study was that significant quantities of additional sustainably biomass could be produced in Brazil, at a comparable cost to, or lower than anywhere else in the world. In this sense, the processing and conversion phases will have more weight role in defining the best feedstock options. An extensive analysis and data on the availability and competitiveness of Brazilian feedstocks for aviation biofuels are presented by Cantarella et al. [36].

An important factor regarding the availability of feedstock for jet biofuel production is the capacity of the feedstock to comply with sustainability requirements. In agreement with the international debate, it is well recognized in Brazil that expansion of agricultural-based feedstock for jet biofuel production can promote land use changes and impact the market for food crops. However, due to the specific characteristics and the dynamic nature of Brazilian agriculture, evidence suggests that indirect effects caused by the expansion of biofuels, in terms of both emissions associated with land use change and the impact on food prices and food security, can be dealt with in Brazil, if adequate precautions are taken [35].

3.1.2. Conversion and Refining Processes. A broad range of conversion and refining technologies for converting various biomass feedstocks was evaluated including gasification, fast pyrolysis, solvent liquefaction, enzymatic hydrolysis of cellulosic and lignocellulosic biomass, alcohol oligomerization (alcohol to jet fuel, ATJ), and hydroprocessing of esters and fatty acids (HEFA), as well as the fermentation of sugars and wastes (i.e., municipal solid wastes, flue gases, and industrial waste residues) to alcohols, to hydrocarbons, and to lipids. All of these technologies have potential to be used in the production of jet biofuel.

In Brazil, fermentation of carbohydrates (sugars) to hydrocarbons or to lipids is approaching the commercial stage, with first-of-a-kind installations coming into operation $[37,38]$, generating two main but different products. The hydrocarbon obtained is an unsaturated $\mathrm{C} 15$ product with four double bonds that would require $4 \%$ hydrogen (by weight) to produce jet biofuels (direct sugar to hydrocarbons, DSHC). The second product is microbial oil, which typically can be a very good feedstock for HEFA conversions.

Lignocellulose is the cheapest feedstock among those studied and can be processed as a whole for conversion into jet biofuels. However, its conversion into synthesis gas (syngas) using gasification (subsequently using FischerTropsch) or into bio-oil using fast pyrolysis or liquefaction (subsequently using hydrogenation/deoxygenation) requires expensive equipment, high temperatures conditions, and energy consumption. The conversion of lignocellulose using FT and HDCJ pathways could be important in the near future as the cost of the relevant equipment declines.

Enzymatic hydrolysis of lignocellulose does not require such expensive equipment; however, the process is slow and needs substantial improvement to provide good quality hydrolysates to supply the large potential demand for fermented biofuels. In addition, cheaper and more efficient enzymes are necessary in order to make enzymatic hydrolysis economically viable. Improvement in the microorganisms to excrete larger amounts of enzymes, working synergistically, would be very advantageous. It is desirable to have enzymes with high turnover rate and more affinity for their substrates, as well as increased robustness to biofuel process conditions.

Fermentation of sugars to alcohols (i.e., bioethanol) is well developed and commercially executed around the world. Brazil has a long tradition in producing bioethanol and this biofuel is currently used as a building block to generate polyethylene in commercial chemical plants, providing a successful example for other upgrading processes such as ATJ 
technology. These alcohols can be easily deoxygenated and oligomerized to jet biofuel by the ATJ processes. Naturally, second-generation sugars (produced from lignocellulose) would improve the sustainability of sugar-derived alternative jet fuel, such as ATJ, DSHC, and some HEFA pathways (i.e., algae oil derived from sugar).

Conversion of vegetable oils to hydrocarbons (HEFA) is a commercial process. However, feedstock is generally expensive, compared to fossil materials, even though the cost can be shared in Brazil with other coproducts such as soy protein. The integration of this process with an existing refinery/power plant would lower costs for the hydrogenation step of the process but requires a process engineering evaluation to evaluate important operational parameters such as hydrogen consumption and compliance with the drop-in requirements.

Conversion of municipal solid wastes and industrial residues by biochemical processes, therefore avoiding the high-temperature conditions of the thermochemical processes applied for cellulosic materials, is being developed and commercial viability for certain routes remains unproven. However, bacterial conversion of flue gases (rich in $\mathrm{CO}$ ) to ethanol was scaled up in two demonstration plants in China by LanzaTech [39] and commercial plants are currently in development [40, 41].

Wastes are often available at negative prices and transforming wastes into useful products should be encouraged, even though their future price may increase to reflect their value. More research is required to know the costs of separation and processing of the different constituents, mainly for municipal solid wastes. Conversion of tallow and yellow greases is possible using the HEFA process, but the limited availability and opportunity cost of these feedstocks are diverting them to biodiesel production under Brazilian conditions.

In summary, feedstock can be discussed according to how close they are and whether they can be converted to the target "Sustainable Aviation Biofuel."

Figure 5 shows, in a simplified way, that materials listed close to the center of the diagram are more costly, but the conversion technology is easier or less costly.

3.1.3. Sustainability Indicators. Sustainability is a fundamental topic to be addressed in establishing a market for the production and use of jet biofuels. There has been much criticism, directed especially toward agriculture, regarding practices involved in biofuels production that would be considered nonsustainable with respect to social and environmental issues. Furthermore, there is increasing pressure, especially from the European market, for the adoption of more sustainable practices in biofuels production. Due to this pressure, stakeholder-driven, international sustainability standards and certification schemes have become more common in the past few years as a way of demonstrating sustainability of the production chain.

As a good example, the sustainability assessment for ethanol production in Brazil has been carried out mostly according to the principles and criteria of Bonsucro, the well-known international sustainability certification standards specific for the sugarcane agroindustry. In addition,

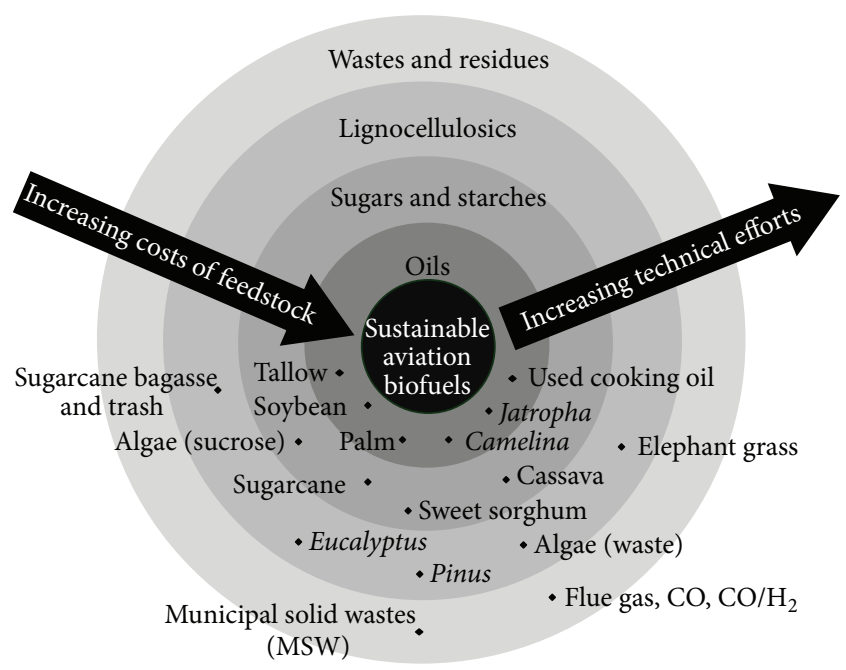

FIGURE 5: Feedstocks and their relative position according to costs and technical effort to be converted to aviation biofuel.

a Roundtable on Sustainable Biomaterials (RSB) and the International Sustainability and Carbon Certification System (ISCC) also contributed to the process. These principles and the criteria adopted are in agreement with those suggested by Goldemberg [42] as appropriate when analyzing sustainability aspects of biofuel production. It is important to discuss these issues, since certification of product and process sustainability will increasingly become a requirement for accessing markets, but the standards and certification processes are complex and require adaptations to the supply chain. The sustainability requirements analyzed were (i) laws and international conventions, (ii) waste production and disposal, (iii) land rights, (iv) Crop management and agrochemical use, (v) employment, wages, and labor conditions, (vi) direct land use changes, (vii) human health and safety, (viii) social and environmental impact assessment, (ix) GHG emissions, (x) rural and social development, (xi) biodiversity and ecosystems, (xii) contractors and suppliers, (xiii) soil conservation, (xiv) engagement and communications with stakeholders, (xv) water use and contamination, (xvi) economic viability and production and processing efficiency, (xvii) air pollution, and (xviii) food security. Considering that this work was the first approach on aviation biofuels perspectives in Brazil, no sustainability targets were proposed to be achieved. For more details about the sustainability requirements considered see Cortez et al. [43].

Although there are important differences among the four common groups of feedstock (sugars and starch, oil, lignocelluloses, and wastes), some general conclusions can be drawn regarding biofuel production and the gaps in practices to comply with sustainability requirements.

In the social sphere, the main positive impacts are the high potential for job creation, income generation, and regional development. While the gaps in practice to achieve sustainability are substantial, the following aspects were common to all groups: a great number of laws and rules, sometimes unclear; different interpretations and lack of knowledge about how to apply laws; uneven enforcement; 
and certain labor laws not adapted to the rural context. There is also a need for qualification and training of workers.

The main potentially positive environmental impact generated by compliance with sustainability requirements of aviation biofuels is reduced GHG emissions compared to fossil fuels, especially from the sucrose and cellulose groups of feedstocks, although there are still some difficulties with the calculations and data.

Brazilian legislation establishes that at least $20 \%$ of the land on individual farms ( $50 \%$ to $80 \%$ in the Amazon region) should be set aside under legal reservation requirements in order to preserve natural resources, including water sources, biodiversity, and refuges for native fauna and vegetation. In addition, stretches of land along water bodies as well as those with slopes above $45^{\circ}$ are regarded as areas of permanent preservation and cannot legally be converted to production.

GHG emissions created by producing ethanol from sugarcane in Brazil over the 2002-2008 period and the expected changes in the expansion from 2008-2020 were analyzed by Macedo et al. [44]. Expansion of ethanol production started in 2002 and led to a very small change in the use of land with native vegetation (less than $1 \%$ ), with a large change in use of low productive pasture lands and some cropping areas (soy and maize). Growth scenarios for 2020 indicate the need for relatively small additional areas (approximately 5 million hectares) to be converted compared to the availability of unused arable lands or degraded pastureland. Thus, if policy and law enforcement are implemented to ensure optimal land use for biofuels, very little impact (if any) from land use change or GHG emissions is expected. Considering the local conditions in Brazil, the area needed for the expansion of aviation biofuels is very small when compared to the areas available for increased cattle raising (30 million hectares) and other areas of unused arable land [44]. That study showed that sugarcane expansion has been independent of (and much smaller than) the growth in other agricultural crops. In all sugarcane expansion areas, the eventual competitors (crops and beef production) also expanded.

Another globally discussed topic in regard to the sustainability of biofuels is the food versus biofuel debate. According to Rosillo-Calle [45], "biofuel production and food security needs to be complementary." It is important to assess food security impacts from biofuel production, but the positive impact of the additional income on agricultural productivity should not be disregarded.

It is equally important to remember the benefits that production of these alternative fuels generate if they meet their most important function, which is to reduce GHG emissions from the whole supply chain when compared to fossil fuels. In Brazil, there is enough land available for the production of food and biomass for biofuels [35, 46-48]. Agricultural expansion has increasingly been taking place in degraded pasture areas and the productivity of livestock has increased significantly, from 0.92 heads/hectare in 2000 to 1.15 heads/hectare in 2010, opening a large area for agriculture [49].

Moraes et al. [50] presented an extensive review of the sustainability challenges from the production of biofuels for aviation in Brazil, considering four groups of feedstocks (sugar and starch, oil, lignocelluloses, and wastes). The work showed the perceptions of more than twenty stakeholders (from the aviation industry, biomass and jet biofuels producers, government, research centers, NGOs, etc.), in regard to eighteen sustainability requirements (as listed previously) and focusing the analysis on sustainability knowledge gaps, technical, financial, and commercial impacts.

3.1.4. Logistics of Jet Fuel. Discussions covering the logistics of production and distribution of jet fuel in Brazil have included quality control requirements and safety procedures associated with jet fuel handling and the impact of introducing jet biofuel on the commercial distribution system. The main stakeholders in the conventional jet fuel distribution chain in Brazil potentially include future jet biofuel producers, the airlines association, international specifications boards, and Brazilian regulatory agencies who participated in the discussion process.

The main conclusions about logistics were as follows:

(a) The logistics of conventional jet fuel in Brazil are well organized. Although consumption is very concentrated in large international airports close to oil refineries, a small fraction goes to regional airports that during part of the year may only be reached by air or by waterways. Furthermore, some regions of the country are supplied almost exclusively by imported jet fuel. All of these important aspects will have to be considered in the implementation of a national policy promoting jet biofuel.

(b) By adopting the concept of "drop-in" jet biofuel, the anticipated barriers to the distribution logistics of jet biofuels, such as recertification of aircraft, changes to airport infrastructure, establishment of quality controls, and traceability and auditing requirements compatible with aviation requirements, are avoided.

(c) Certainly, some commercialization gaps and barriers remain, mainly concerning the transport and logistics of biofuel before the blending point and the lack of technical and legal requirements for the blender. Although the commercial use of jet biofuels is properly regulated by ANP's Resolution number 20/2013 [51], the standards for production of jet biofuels remain to be established.

(d) Of the 13 largest airports responsible for $85 \%$ of jet fuel consumption in Brazil, 10 are primarily supplied by nearby oil refineries, 2 are supplied through oceanbased imports (7\%), and only Brasilia International airport $(6 \%)$ is supplied by tanker trucks from a refinery 700 kilometers away [2]. Therefore, the best alternative for finishing the biofuel, preparing the blend, and issuing a certificate of quality for each batch of jet biofuel is a terminal near the relevant airport and suppliers. On the other hand, an airport such as Brasilia's, which consumes approximately 0.5 million cubic meters of jet fuel a year, is distant from any refinery but close to feedstock production sites 
and could benefit economically if the "drop-in" point was nearby.

Since the initial processing of agricultural feedstock should occur close to production for economic reasons, subsequent logistics associated with jet biofuel production require detailed assessments of each type of feedstock and production processes to maximize economic benefits, harmonizing social and environmental issues.

\subsubsection{The Identified Pathways and R\&D Gaps}

(1) Identified Pathways. After discussing potential feedstocks and refining processes for producing renewable jet fuel, multiple possible pathways were identified. Certification requirements for use in commercial aviation are established internationally according to ASTM D7566 [16], which contains one special annex for each approved alternative jet fuel production process. Figure 6 presents an overview of all identified pathways pertinent to Brazil, including the denomination and status of the ASTM approval process. As depicted, two of the final jet fuel production processes are already approved (see ASTM's gates white boxes in Figure 6) and several others are still under analysis by ASTM's Emerging Fuels Committee.

After pretreatment, possible feedstocks are submitted to different conversion processes identified here as lipid conversion or biochemical and thermochemical processes. The final stages of jet biofuel production are usually like oil refinery processes.

While some lipid conversion and thermochemical processes have already been already approved by ASTM, the various biochemical conversion routes still require approval.

(2) R\&D and Commercialization Gaps. In broader terms, R\&D programs with defined objectives that take into consideration the goals of aviation biofuel production need to be created and a large number of potential pathways considered. The $\mathrm{R} \& \mathrm{D}$ aviation biofuels program must meet the following objectives to overcome existing gaps:

(i) ensuring the pathway is technically feasible and commercially viable;

(ii) reducing GHG emissions from the perspective of a full life cycle analysis (in cases where net GHG emissions of biofuels are too high to justify their use);

(iii) reducing production costs, so that the final market price (production cost + profit margin) of biofuels meets the jet fuel market price;

(iv) improving the environmental and socioeconomic indicators, where these benefits are still not significant.

Commercially, it is important to recognize that successful biofuels have built their economic viability on valuable coproducts. This was the case with ethanol from Brazilian sugarcane where sugar might be regarded as the coproduct, in American corn ethanol which produces dried distiller's grain used as animal feed and biodiesel from soybean in various countries, where soybean cake is produced as a commercial feed. Of course size and characteristics of the coproduct market will determine how the economic equation for biofuels and coproducts will be built. However, it is recognized that when for aviation biofuels are considered, an important strategy to achieve lower cost biofuels is by developing high value coproducts. It is worth mentioning that generally the processes produce not only jet biofuel but also renewable diesel and gasoline, which should be considered together in an integrated biofuels program.

Besides the above drivers for R\&D program definition, it is also essential to define an R\&D strategy (approach) to be followed. This will determine the effort, reflected by the amount of financial and human resources to be invested, as well as future accomplishments and benefits.

(3) R\&D for Identified Pathways. The lipid conversion route is well established and is approved by ASTM as HEFA (hydroprocessed fatty acid esters and free fatty acids). The investment cost for hydroprocessing is low, but the cost of feedstock can represent more than $70 \%$ of the total cost [52]. The availability of inexpensive hydrogen could significantly affect the final cost. The main constraint in this case is a commercial one. The Brazilian Biodiesel Program, well established in the market since 2005, competes for the same feedstock, plant oil, tallow, and used cooking oil. Eventual niche markets supplying airports distant from refineries but near agricultural areas fields could be promoted by the production of hydrogen from biomass, an aspect that needs to be developed in Brazil. The high productivity of oil palm needs has to be explored for Brazilian conditions, and R\&D into production method needs incentives. R\&D on other oilproducing plants can help to improve output on lands that are not presently used for agriculture, but the production of biofuels in Brazil needs to be treated in an integrated way to avoid the competition for feedstock between jet biofuel and biodiesel. Another possible feedstock is microbial lipid produced by the fermentation of soluble sugars (heterotrophic) or directly produced by algae (phototrophic). The R\&D gaps associated with these pathways range from applied biology to improved microbe stability, to construction of demonstration units large enough to obtain competitive costs. If cellulose can be used as a feedstock, some cost benefits are expected in the long run.

The biochemical conversion route actually includes diverse feedstocks such as municipal solid waste, flue gas (from industrial waste and residues) that is rich in carbon monoxide and fermentable sugars, either from plants, from starch conversion, or from hydrolysis of cellulosic material. Most of the pathways produce alcohols as intermediate products that are transformed into jet biofuel through the ATJ process, which may be one of the next processes approved by ASTM. The other possible route is direct sugar to hydrocarbon (DSHC) which has also been submitted to ASTM and uses genetically modified microbes to convert sugar, followed by soft hydrogenation to obtain jet biofuel.

There are several R\&D gaps to be filled according to the development stage of each particular pathway, for example, 


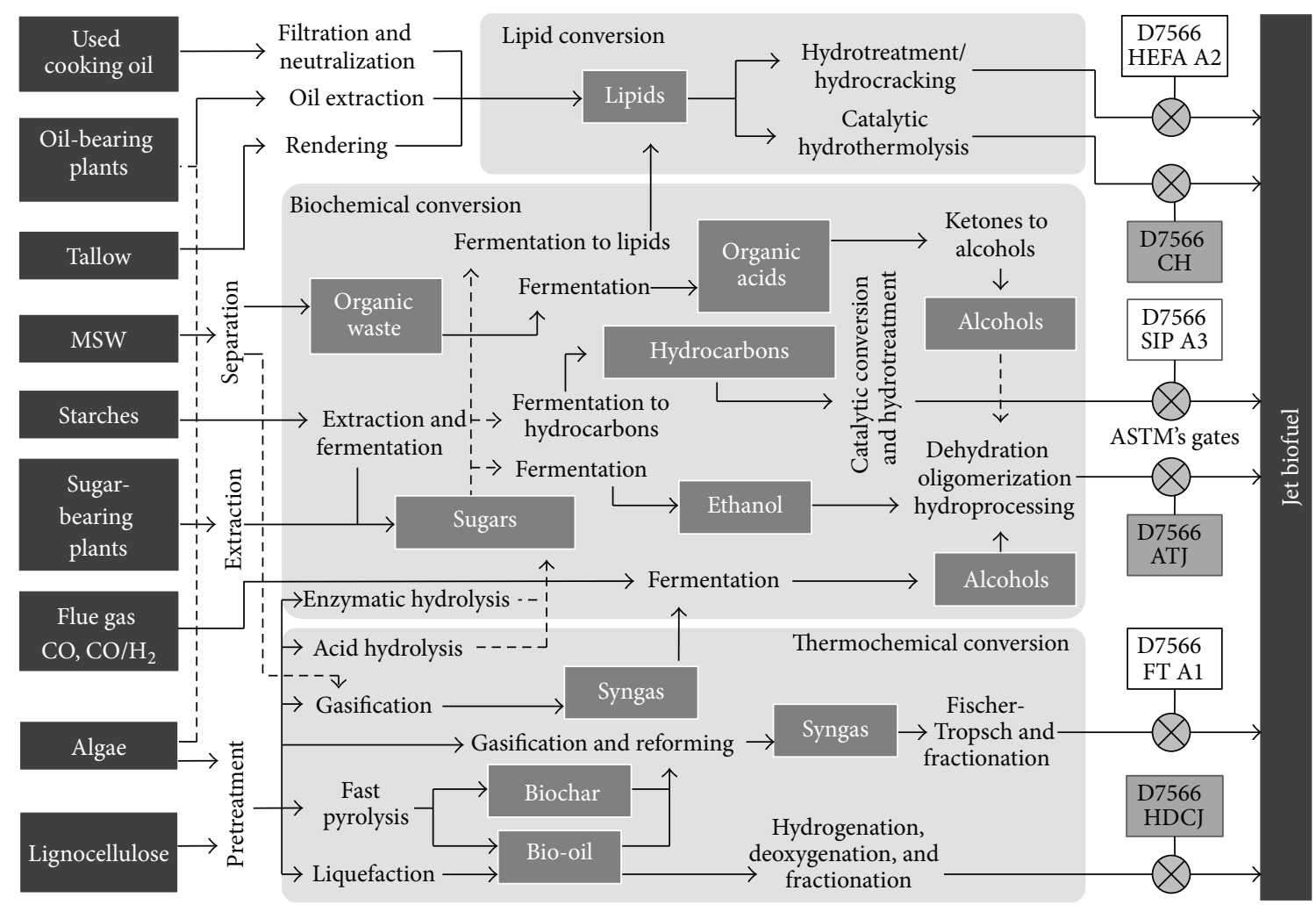

FIGURE 6: Identified pathways for the production of sustainable jet biofuels in Brazil.

developing more selective catalysts to convert alcohols more efficiently to jet fuel; improving the conversion efficiency of sugars to hydrocarbon; developing microbes more resistant to contamination by gas produced through gasification; advanced municipal waste separation and improving fermentation of the organic fraction; reducing the cost of enzymatic hydrolysis to produce fermentable sugars or ethanol; and moving past the demonstration phases and reaching commercial units for all the pathways.

The main commercial difficulty for the pathways that involve sugars or ethanol is that market price of these intermediate products is high due to possible uses as food or for road transport fuel. Due to the extensive Brazilian experience in producing sugar and ethanol from sugarcane and the existence of a well established agroindustrial sector dedicated to the field, the natural reference price for liquid biofuels most likely will be ethanol. In energy terms, actual ethanol consumption in Brazil as road transport fuel is more than one and a half times all aviation fuel consumption [2]. Once again, it is probably necessary to establish a governmental program to develop Brazilian aviation biofuels in an integrated way to avoid the competition for feedstock between aviation and road transport.

The main feedstock for the thermochemical route is lignocellulose, which is available in sufficient amounts in Brazil to substitute all conventional liquid fuels in the country. An ASTM-approved pathway using this route to produce jet biofuel via Fischer-Tropsch process already exists. The origin of the lignocellulosic material can be sugarcane bagasse, wood waste, or forestry residues.

Although the cost of the raw material in the field can be very low, the transportation cost is important and limits the size of the processing plant, with large implications for investment cost. Another possible route using lignocellulosic biomass is to start with pyrolysis, to obtain bio-oil and biochar as intermediate products that could be transported economically over longer distances, and then be submitted to gasification and synthesis by the Fischer-Tropsch process. The cost of the process is still considered high due to the very special conditions required by the reactions (high temperature and pressure), demanding large reactors to reduce cost.

The main development gap in this pathway comprises the gasification and gas-cleaning processes that are not designed for the available Brazilian biomass. A promising alternative pathway to Fischer-Tropsch, which is being investigated mostly outside Brazil, is to produce a bio-oil through fast pyrolysis or solvent liquefaction, which could be upgraded in an existing refinery, and reducing the costs. The transformation of the bio-oil to jet biofuel is done by deoxygenation. The main R\&D gap in this case is that hydrodeoxygenation of biooils requires extreme conditions of temperature and pressure, with specific catalysts and expensive hydrogen.

3.2. Summary of Limiting Factors and Policy Recommendations for Brazil. Table 1 presents a preliminary list of limiting factors and policy recommendations for the development of 


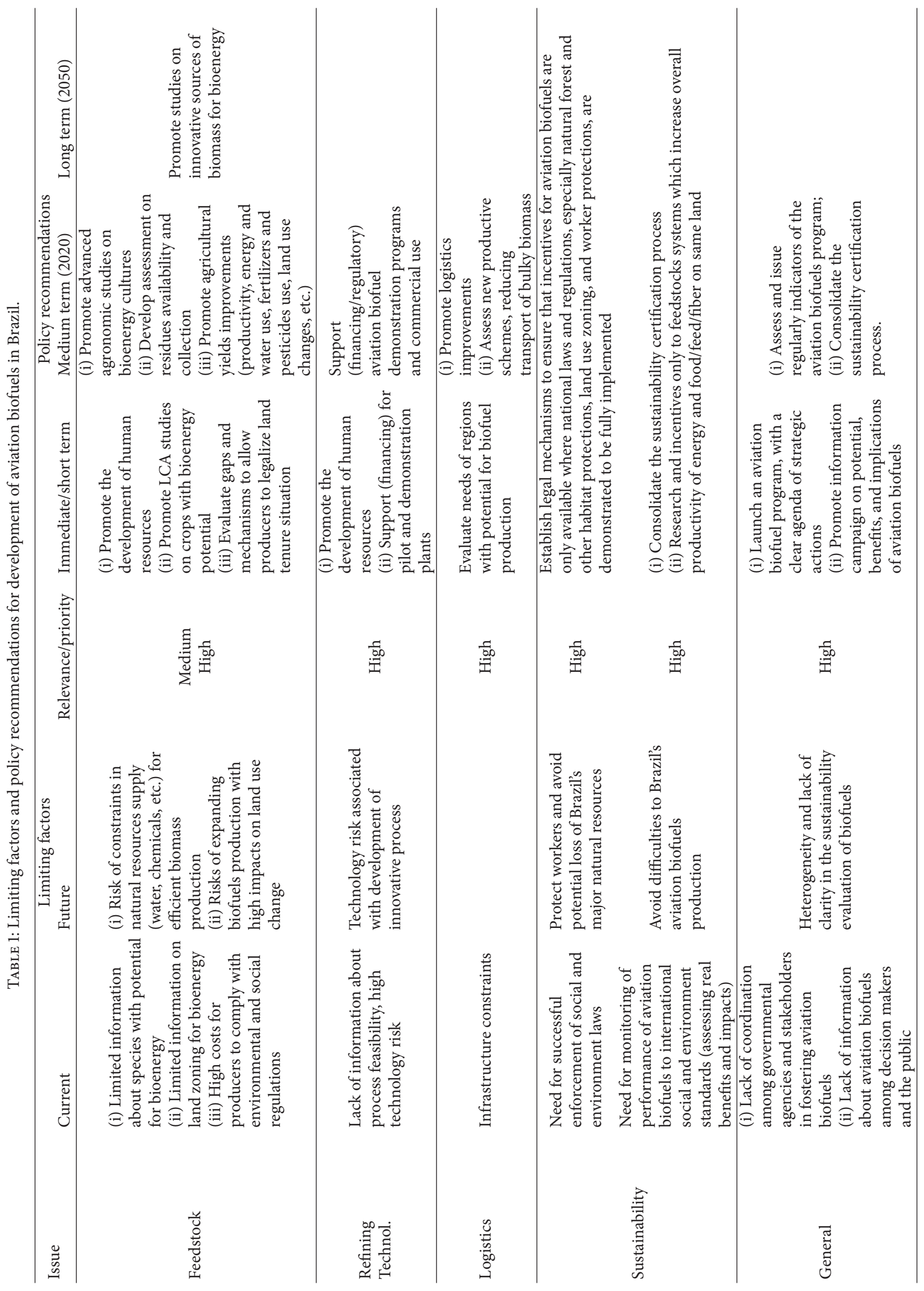


aviation biofuel, answering the questions already raised and taking into account the particular Brazilian context. More information is available in Cortez et al. [43].

\section{Conclusions}

The work reported here was an enriching experience involving important stakeholders from different sectors of society including government, agriculture, the aviation industry, regulatory agencies, NGOs, universities, and research institutions and proved to be an endogenously creative project and a substantive Brazilian contribution to a sustainable aviation industry.

Substitution of fossil fuels for aviation represents a very important opportunity for sustainable biofuels and Brazil has a position of significant comparative advantage in this area and could become a global contributor. There are important challenges to be overcome to create the basis for this new industry in all three segments (feedstocks, refining technologies, and logistics). Only some bioenergy options are sustainable, so the fuels should be developed and used by applying strong sustainability criteria and verification to meet the needs of the aviation industry as well as society. Producers of some crops could benefit from more mature agronomic experience, while other crops show good potential but have not yet been put into large-scale production. Based on these arguments, no alternative can be excluded at this stage, justifying a careful screening of the several supply chains available.

\section{Disclaimer}

Any opinions, findings, and conclusions or recommendations expressed in this paper are those of the authors and do not necessarily reflect the views of the funding parties, including The Boeing Company and Embraer S.A.

\section{Conflict of Interests}

The authors declare that there is no conflict of interests regarding the publication of this paper.

\section{Acknowledgments}

The Roadmap Sustainable Aviation Biofuels for Brazil was funded by Boeing, Embraer, FAPESP (Project 2012/500091 ), and several other sponsors. The authors acknowledge the important contributions of the project members (researchers, administrative team, and consultants).

\section{References}

[1] IEA, World Energy Outlook 2013, OECD, IEA, Paris, France, 2013.

[2] ANP, Anuário Estatístico Brasileiro do Petróleo, Gás Natural e Biocombustíveis, Agência Nacional do Petróleo (ANP), Rio de Janeiro, Brazil, 2012.
[3] EPE, Plano Decenal de Expansão de Energia 2020, EPE, Brasília, Brazil, 2020.

[4] IATA, Annual Report 2010, International Air Transport Association (IATA), Berlin, Germany, 2010.

[5] McKinsey \& Company, Estudo do Setor de Transporte Aéreo do Brasil, McKinsey \& Company, Rio de Janeiro, Brazil, 2010.

[6] S. Gössling and P. Upham, Climate Change and Aviation: Issues, Challenges and Solutions, Earthscan, London, UK, 2009.

[7] F. E. Nigro, “The Brazilian/São Paulo perspectives for renewable fuels," in Proceedings of the 1st Sustainable Aviation Biofuel for Brazil Project Workshop, FAPESP, São Paulo, Brazil, April 2012.

[8] J. Han, A. Elgowainy, J. B. Dunn, and M. Q. Wang, "Life cycle analysis of fuel production from fast pyrolysis of biomass," Bioresource Technology, vol. 133, pp. 421-428, 2013.

[9] D. S. Lee, D. W. Fahey, P. M. Forster et al., "Aviation and global climate change in the 21st century," Atmospheric Environment, vol. 43, no. 22-23, pp. 3520-3537, 2009.

[10] D. S. Lee, G. Pitari, V. Grewe et al., "Transport impacts on atmosphere and climate: aviation," Atmospheric Environment, vol. 44, no. 37, pp. 4678-4734, 2010.

[11] T. K. Hari, Z. Yaakob, and N. N. Binitha, "Aviation biofuel from renewable resources: routes, opportunities and challenges," Renewable and Sustainable Energy Reviews, vol. 42, pp. 12341244, 2015.

[12] K. Lokesh, V. Sethi, T. Nikolaidis, E. Goodger, and D. Nalianda, "Life cycle greenhouse gas analysis of biojet fuels with a technical investigation into their impact on jet engine performance," Biomass and Bioenergy, vol. 77, pp. 26-44, 2015.

[13] OAG, The European Union Emissions Trading Scheme, OAG, Luton, UK, 2012.

[14] IATA, "Climate action: reducing emissions from aviation," 2014, http://ec.europa.eu/clima/policies/transport/aviation/index_en .htm.

[15] IATA, "Resolution on the implementation of aviation 'CNG2020' strategy,' 5, 2013, http://www.iata.org/pressroom/ pr/Documents/agm69-resolution-cng2020.pdf.

[16] ASTM International, "Standard specification for aviation turbine fuel containing synthesized hydrocarbons," ASTM D 7566, ASTM International, West Conshohocken, Pa, USA, 2011.

[17] ASTM International, "Standard specification for aviation turbine fuels," ASTM D 1655, ASTM International, West Conshohocken, Pa, USA, 2013.

[18] P. Gegg, L. Budd, and S. Ison, "The market development of aviation biofuel: drivers and constraints," Journal of Air Transport Management, vol. 39, pp. 34-40, 2014.

[19] P. Gegg, L. Budd, and S. Ison, "Stakeholder views of the factors affecting the commercialization of aviation biofuels in Europe," International Journal of Sustainable Transportation, vol. 9, no. 8, pp. 542-550, 2015.

[20] G. Liu, B. Yan, and G. Chen, "Technical review on jet fuel production," Renewable and Sustainable Energy Reviews, vol. 25, pp. 59-70, 2013.

[21] N. Winchester, D. McConnachie, C. Wollersheim, and I. A. Waitz, "Economic and emissions impacts of renewable fuel goals for aviation in the US," Transportation Research Part A: Policy and Practice, vol. 58, pp. 116-128, 2013.

[22] D. Chiaramonti, M. Prussi, M. Buffi, and D. Tacconi, "Sustainable bio kerosene: process routes and industrial demonstration activities in aviation biofuels," Applied Energy, vol. 136, pp. 767774, 2014. 
[23] H. T. Murphy, D. A. O'Connell, R. J. Raison et al., "Biomass production for sustainable aviation fuels: a regional case study in Queensland," Renewable and Sustainable Energy Reviews, vol. 44, pp. 738-750, 2015.

[24] ICAO, ICAO Review: Sustainable Alternative Fuels for Aviation, ICAO, Québec, Canada, 2011, http://www.icao.int/ environmental-protection/Documents/SUSTAF Review[2].pdf.

[25] WEF, "Global Aviation Biofuel Initiatives Database," 2014, http://www.weforum.org/best-practices/biofuels/.

[26] ABRABA, "Aliança Brasileira para Biocombustíveis de Aviação," 2012, http://www.abraba.com.br/pt-BR/Paginas/home.aspx.

[27] TAM, "TAM realiza com sucesso primeiro voo com biocombustível de pinhão manso da América Latina," 2010, http://www.tam.com.br/b2c/vgn/v/index.jsp?vgnextoid= c88561db4cdac210VgnVCM1000009508020aRCRD.

[28] Embraer, "Azul Brazilian Airlines makes demonstration flight with renewable jet fuel produced from Brazilian sugarcane," 2012, http://www.embraer.com/en-us/imprensaeventos/pressreleases/noticias/pages/azul-linhas-aereas-realiza-voo-experimental-bem-sucedido-com-biocombustivel.aspx.

[29] ICAO, Flightpath to a Sustainable Future: The Rio+20 Global Biofuels Initiative, ICAO, Québec, Canada, 2012.

[30] Boeing, Embraer, FAPESP, and UNICAMP, "Flightpath to Aviation BioFuels in Brazil: Action Plan," São Paulo, Brazil, 2013, http://www.fapesp.br/publicacoes/flightpath-to-aviation-biofuels-in-brazil-action-plan.pdf.

[31] ANP, "Demanda e Oferta do Transporte Aéreo," 2014, http:// www2.anac.gov.br/estatistica/demandaeoferta/.

[32] IEA, Medium-Term Oil Market Report 2015, IEA, Paris, France, 2015.

[33] IBGE, Censo Agropecuário 2006, IBGE, Rio de Janeiro, Brazil, 2006.

[34] IBGE, Produção Agrícola Municipal: Culturas Temporárias e Permanentes 2009, IBGE, Rio de Janeiro, Brazil, 2009.

[35] A. M. Nassar, L. Harfuch, M. M. R. Moreira, L. B. Bachion, L. B. Antoniazzi, and R. C. Lima, "Simulating Land Use and Agriculture Expansion in Brazil: Food, Energy, AgroIndustrial and Environmental Impacts," São Paulo, Brazil, 2011, http://www.iconebrasil.com.br/datafiles/publicacoes/artigos/ 2002/simulating_land_use_and_agriculture_expansion_in_brazil_0902.pdf.

[36] H. Cantarella, A. M. Nassar, L. A. B. Cortez, and R. Baldassin Junior, "Potential feedstock for renewable aviation fuel in Brazil," Environmental Development, vol. 15, pp. 52-63, 2015.

[37] Amyris, "Amyris Ships First Truckload of Biofene From Its New Plant in Brazil," 2013, https://amyris.com/amyris-shipsfirst-truckload-of-biofene-from-its-new-plant-in-brazil/.

[38] Solazymes, "Solazyme Accelerates U.S. Commercialization for Renewable Oils Production with Archer-Daniels-Midland Company Agreement," 2012, http://investors.solazyme.com/ releasedetail.cfm?releaseid $=721368$.

[39] LanzaTech, "LanzaTech Announces Energy Industry Veteran Ken C. Lai to Lead China Operations," 2013, http://www.lanzatech.com/lanzatech-announces-energy-industry-veteran-kenc-lai-to-lead-china-operations/.

[40] D. Bacovsky, M. Dallos, and M. Worgetter, Status of Advanced Biofuels Demonstrations Facilities in 2012: A Report to IEA Bioenergy Task 39, International Energy Agency/IEA, 2013.

[41] D. Bacovsky, M. Dallos, and M. Worgetter, "Status of 2nd Generation Biofuels Demonstration Facilities in June 2010," 2010.
[42] J. Goldemberg, "A Historical Account of Bioenergy Production in Brazil," 2011.

[43] L. A. B. Cortez, F. E. Nigro, A. M. Nassar et al., "Roadmap for sustainable aviation biofuels for Brazil: A flighpath to aviation biofuels in Brazil, Blucher, São Paulo," 2014, http:// openaccess.blucher.com.br/article-list/roadmap-aviation-272/ list\#articles.

[44] I. C. Macedo, J. E. A. Seabra, and J. E. A. R. Silva, "Green house gases emissions in the production and use of ethanol from sugarcane in Brazil: the 2005/2006 averages and a prediction for 2020," Biomass and Bioenergy, vol. 32, no. 7, pp. 582-595, 2008.

[45] F. Rosillo-Calle, "Food versus fuel: toward a new paradigmthe need for a Holistic Approach," ISRN Renewable Energy, vol. 2012, Article ID 954180, 15 pages, 2012.

[46] CGEE, Sustainability of Sugarcane Bioenergy, CGEE, MCT, Brasília, Brazil, 2012.

[47] J. Goldemberg, S. T. Coelho, and P. Guardabassi, “The sustainability of ethanol production from sugarcane," Energy Policy, vol. 36, no. 6, pp. 2086-2097, 2008.

[48] J. Goldemberg, “The Brazilian biofuels industry," Biotechnology for Biofuels, vol. 1, article 6, 2008.

[49] FIESP and ICONE, “Outlook Brasil 2022," 2012, http://icna .org.br/sites/default/files/artigo/Outlook Brasil 2022.pdf.

[50] M. A. F. D. Moraes, A. M. Nassar, P. Moura, R. L. V. Leal, and L. A. B. Cortez, "Jet biofuels in Brazil: sustainability challenges," Renewable and Sustainable Energy Reviews, vol. 40, pp. 716-726, 2014.

[51] ANP, "Resolução ANP 20/2013, Brasil," 2013, http://nxt.anp .gov.br/NXT/gateway.dll/leg/resolucoes_anp/2013/junho/ranp\% $2020 \% 20-\% 202013 . x m l ? \mathrm{f}=$ templates $\$ \mathrm{fn}=$ document - frame.htm $\$ 3.0 \$ \mathrm{q}=\$ \mathrm{x}=$.

[52] EC, “2 Million tons per year: a performing biofuels supply chain for EU aviation," August 2013, https://ec.europa.eu/energy/ sites/ener/files/20130911_a_performing_biofuels_supply_chain .pdf. 

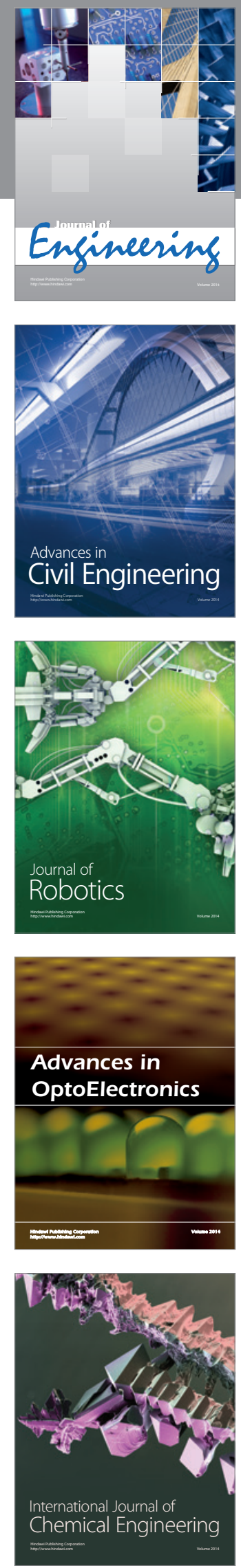

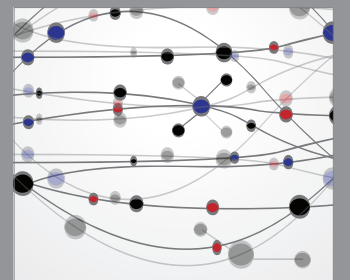

The Scientific World Journal
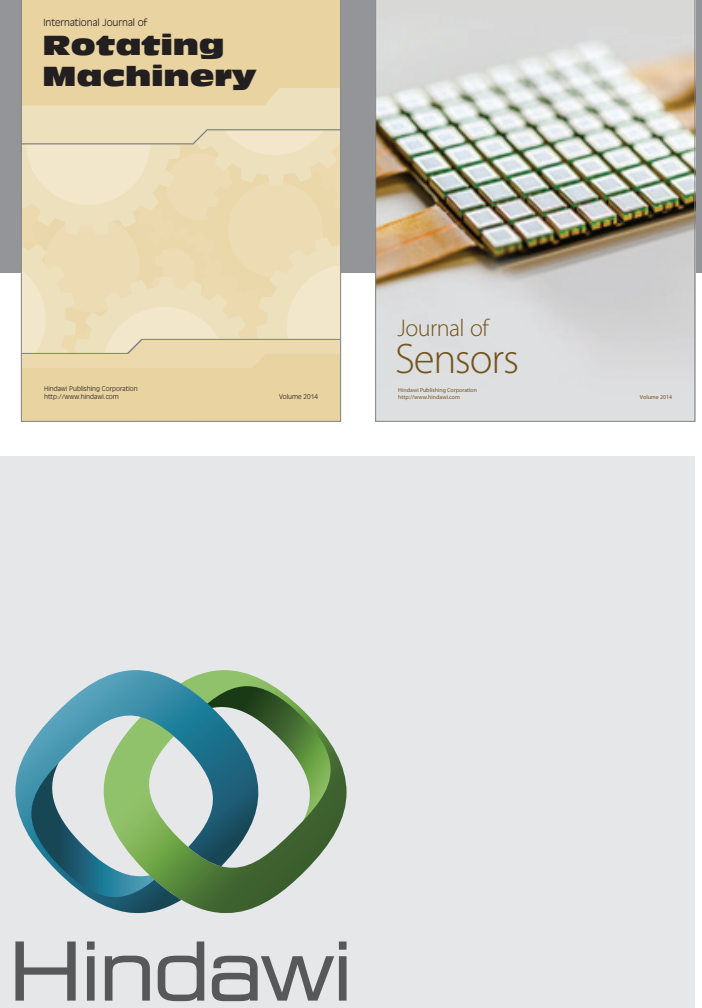

Submit your manuscripts at http://www.hindawi.com
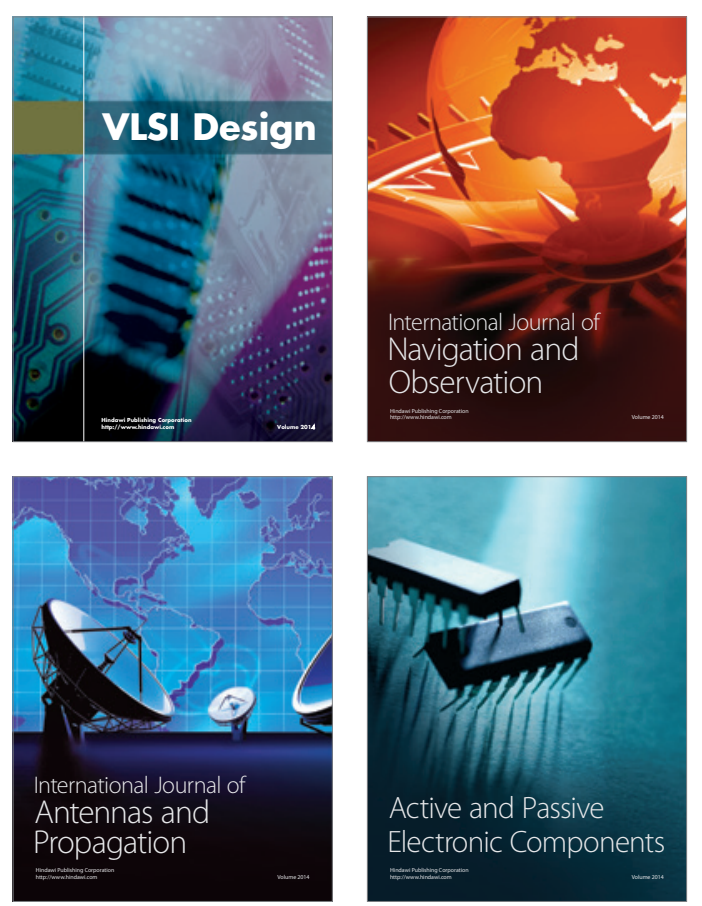
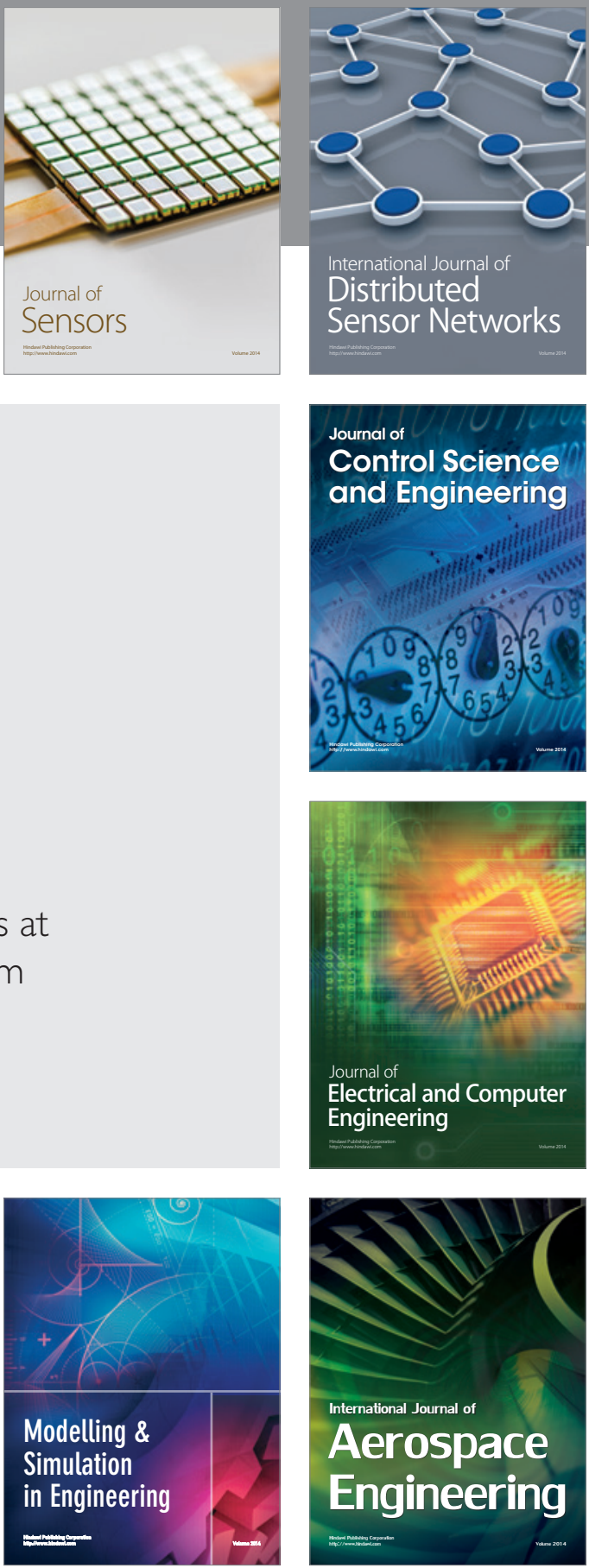

Journal of

Control Science

and Engineering
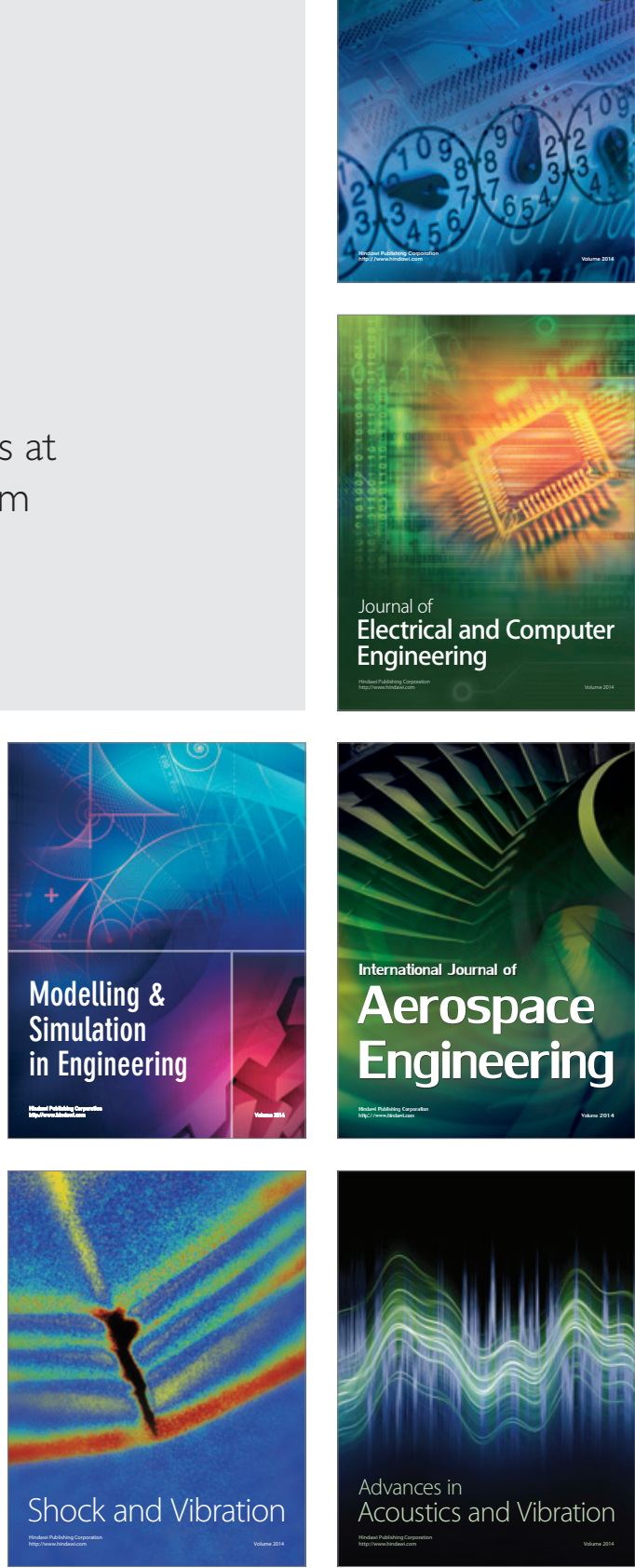